\title{
Pillow use: the behavior of cervical stiffness, headache and scapular/arm pain
}

\author{
Susan J Gordon ${ }^{1,2}$ \\ Karen A Grimmer-Somers ${ }^{3}$ \\ Patricia $\mathrm{H}$ Trott $^{4}$ \\ 'Associate Professor, School of \\ Public Health, Tropical Medicine and \\ Rehabilitation Sciences, James Cook \\ University, Townsville, Australia; \\ ${ }^{2}$ Member, International Centre for \\ Allied Health Evidence, University of \\ South Australia, Australia; ${ }^{3}$ Professor \\ of Allied Health, School of Health \\ Sciences, University of South \\ Australia, Director, International \\ Centre for Allied Health Evidence, \\ University of South Australia, \\ Australia; ${ }^{4}$ Associate Professor, School \\ of Health Sciences, University of \\ South Australia
}

This article was published in the following Dove Press journal: Journal of Pain Research 10 August 2010

Number of times this article has been viewed

Background: Pillows are intended to support the head and neck in a neutral position to minimize biomechanical stresses on cervical structures whilst sleeping. Biomechanical stresses are associated with waking cervical symptoms. This paper adds to the scant body of research investigating whether different pillow types produce different types and frequencies of waking symptoms in asymptomatic subjects.

Methods: A random-allocation block-design blinded field trial was conducted in a large South Australian regional town. Subjects were side-sleepers using one pillow only, and not receiving treatment for cervicothoracic problems. Waking cervical stiffness, headache and scapular/arm pain were recorded daily. Five experimental pillows (polyester, foam regular, foam contour, feather, and latex) were each trialed for a week. Subjects' 'own' pillow was the control (a baseline week, and a washout week between each experimental pillow trial week). Subjects reported waking symptoms related to known factors (other than the pillow), and subjects could 'drop out' of any trial pillow week.

Results: Disturbed sleep unrelated to the pillow was common. Waking symptoms occurring at least once in the baseline week were reported by approximately $20 \%$ of the subjects on their 'own' pillow. The feather trial pillow performed least well, producing the highest frequency of waking symptoms, while the latex pillow performed best. The greatest number of 'drop outs' occurred on the feather pillow. The foam contour pillow performed no better than the foam regular pillow.

Conclusion: 'Own' pillows did not guarantee symptom-free waking, and thus were a questionable control. The trial pillows had different waking symptom profiles. Latex pillows can be recommended over any other type for control of waking headache and scapular/arm pain.

Keywords: pillow type, cervical stiffness, arm pain, headache

\section{Introduction}

The main role of a pillow during sleep is to support the cervical spine in a neutral position. ${ }^{1-6}$ This prevents adoption of more 'end-range' cervical spine postures during sleep, which are believed to increase biomechanical stresses on cervical spine structures. This can compromise pain-sensitive structures and produce waking symptoms, such as cervical pain and stiffness, headache, scapular or arm pain. ${ }^{7,8}$ Recent research on the effect of different pillow types for subjects with chronic neck pain found that soft pillows which supported the cervical lordosis, ${ }^{9}$ and pillows with a sleeping neck support, ${ }^{10}$ provided effective relief for waking pain. However, there is scant research on the effect of different pillow types on the production of waking symptoms in healthy subjects. Consequently different pillow types have

Correspondence: Susan Gordon Discipline of Physiotherapy, James Cook University, Townsville, Australia

Tel +61747816734

Fax $+6|7478| 6868$

Email susan.gordon2@jcu.edu.au 
proliferated in the market place over recent years, with accompanying but variably-evidenced claims that they produce symptom-free sleep, no waking symptoms, and/ or high quality sleep experiences.

Our telephone survey of over 800 randomly-selected participants without diagnosed cervical problems in a large South Australian rural town (9.6\% total town population), identified a surprisingly high frequency of waking symptoms. ${ }^{11,13}$ At least once in a usual week, 27\% reported waking with scapular or arm pain, 19\% with a headache, and $17 \%$ with cervical pain and/or stiffness. Moreover subjects commonly reported waking with more than one of these symptoms. As anticipated from De Koninck et al's research, ${ }^{12}$ we found that side sleepers who slept on one pillow were most common across age groups and in both genders (over 65\% in each of young, middle and old age categories, and over $70 \%$ of men and women). ${ }^{11,13}$ These single-pillow side-sleepers reported using a variety of pillows types, most commonly polyester regular pillows (approximately 40\%), followed by foam pillows (approximately 19\%) contour (approximately 12\%) and regular (approximately 8\%), rubber (latex) pillows (approximately 14\%), and feather pillows (approximately 9\%). Pillow age varied from a few days to over 5 years. ${ }^{11,13}$

This paper reports findings from our recent experimental study which investigated whether waking symptoms were produced by any of 5 trial pillows, and whether there were differences in frequency of waking symptoms. The trial pillows were new versions of those most commonly reported in our telephone survey. ${ }^{11}$ We recently reported on the influence of the 5 trial pillows compared with subjects' 'own' pillow on waking cervical pain, where latex pillows were least likely be associated with waking cervical pain, and feather pillows were most likely. ${ }^{14}$ This paper reports on the frequency of other common waking symptoms (cervical stiffness, headache and scapular/arm pain) associated with the trial and 'own' pillows.

\section{Method}

Ethic approval was provided by the University of South Australia Human Research Ethics Committee.

\section{Study design}

A random-allocation block-design blinded field trial was undertaken in subjects' homes in the same town as the earlier telephone survey. ${ }^{11}$

\section{Pillows tested}

The trial pillows comprised:

- Polyester pillows (provided by Australian pillow manufacturer: Tontine, (East Brunswick, Victoria)

- Foam regular (Comfort Classic) and foam contour (Medirest) pillows provided by Australian pillow manufacturer Dentons, (Wantirna South, Victoria)

- Standard Dunlopillo latex pillows provided by the University of South Australia

- Feather pillows purchased from Target, an Australia-wide retail chain

The depth of the trial pillows at maximum height ranged from 115 to $142 \mathrm{~mm}$, width varied from 45 to $46 \mathrm{~cm}$, and length from 70 to $73 \mathrm{~cm}$. Apart from supplying the trial pillows, there was no additional involvement of pillow manufacturers.

The comparison pillow was the participants' 'own' pillow, which was assumed to be the best performing pillow that participants had encountered, and would thus provide a reasonable reference standard for each subject. We placed no limitation on the nature of 'own' pillow, and thus it could be of any type, age, or state of wear and tear.

\section{Sample size calculation}

No studies were available on which to base sample size calculations. A small difference in waking symptoms was conservatively estimated when comparing responses to subjects' 'own' pillow and any trial pillow (0.20). Cohen's power table ${ }^{15}$ indicated that a sample size of 500 observations on each pillow was required to detect a small effect with $\alpha=0.05, \beta=0.99$, taking account of correlated results from the same subjects, sleeping on the same pillow over repeated nights of testing.

\section{Study management}

The trial pillows were randomly allocated into a five-block administration-order by an independent research administrator, who also randomly allocated subjects to blocks, coordinated pillow delivery and collection, and collated study data.

\section{Pillow blinding}

The data analyst was blinded to block design and pillow type. Attempts were made to blind subjects, by de-identifying trial pillows (removing labels and covers, numbering them and placing them in plain pillow cases). This was an attempt to enhance subject blinding to pillow type, although the shape and feel may have constrained blinding for some subjects familiar with some pillow types. 


\section{Participants}

A purposive age-gender cluster sample was conveniently recruited from participants in our earlier studies. ${ }^{11,13}$ Clusters in which there were insufficient participants were completed by respondents to local newspaper advertisements. Age clusters were categorized as 18-40 years (young), 41-59 years (middle), and 60 years and over (old), and the proportion of the sample in each reflected the reference population at the time. ${ }^{16}$ There was no evidence that the study sample was biased by intention to demonstrate superiority of one pillow type over other. Participants did not gain financially or materially according to their responses.

\section{Inclusion criteria}

The study included generally healthy people aged over 18 years, who generally slept on their side with 1 pillow, and were not actively seeking medical treatment for cervicothoracic spine symptoms during the study.

\section{Exclusion criteria}

People who were not usually side sleepers, regularly used more than 1 pillow, or reported trauma or disease affecting the cervicothoracic spine in the preceding year.

\section{Data collection}

Outcome data were recorded on a 7-day-night diary for each pillow. Subjects reported both retiring and waking cervical stiffness, headache and scapular pain. Duration of waking symptoms was recorded in categories of an hour or less, half a day and all day. On each occasion that participants reported waking symptoms, they reported any identifiable cause (apart from the pillow).

\section{Pillow intervention}

Data was initially captured on subjects' 'own' pillow for a week (7 consecutive nights) to establish baseline 'usual' symptoms. Over the next 9 weeks, subjects in each treatment-administration block tested the trial pillows for 7 consecutive nights each, interspersed by 7 night's sleep on their 'own' pillow. Returning to their 'own' pillow for 1 week between using each trial pillow provided a 'washout period', allowing subjects to return to their 'normal' waking symptom state. ${ }^{17}$ Subjects were encouraged to test each trial pillow for the whole 7 nights, unless symptom production, or lack of sleep, necessitated cessation of its use.

\section{Invalid data}

Throughout the trial, data relating to the occasions on which subjects reported the presence of waking symptoms associated with identifiable causes (other than the pillow) were excluded from analyses. These data were called 'invalid' and its exclusion then identified a homogenous sample for whom the pillow was the likely reason for waking symptoms.

\section{Drop outs}

Subjects who dropped out of any week's test of a particular trial pillow were also identified, and the amount of 'missing' data was quantified. This allowed analysis of data from those subjects who recorded a valid waking symptom score each day, as well as those subjects who dropped out at any point throughout the trial period.

\section{Cumulative symptom scores}

Cumulative scores were determined for the number of days in each trial pillow week that subjects woke with each symptom. Weekly symptom duration scores were constructed using arbitrarily-ranked values. The frequency and duration scores were combined as a per-week symptom frequency-duration score per pillow:

- subjects who woke without symptoms on any day were assigned a score of 0

- subjects who woke with symptoms lasting up to 30 minutes on any day were assigned a score of 0.5 (half an hour)

- subjects whose waking symptoms on any day lasted half a day were assigned a score of 12 (12 hours) and

- subjects whose waking symptoms on any day lasted all day were assigned a score of 18 (18 hours)

\section{Clusters of waking symptom cumulative scores}

We clustered the cumulative waking symptom scores for each pillow, classifying the clusters as no symptom ( 0 score), occasional short term symptom (1-3 days of any symptom lasting 30 minutes), regular short term symptom (4-7 days of any symptom lasting 30 minutes), occasional half day symptom (1-3 days of any symptom lasting half a day), regular half day symptom (4-7 days of any symptom lasting half a day) and longer term symptoms (regular symptoms lasting for longer).

\section{Analysis}

This paper reports on the effect of the trial pillows using three outcome measures: 1) any reports of waking cervical stiffness, headache and scapular/arm pain symptoms, 2) weekly symptom duration scores, and 3) clusters of waking symptom cumulative scores. It considers commonalities of responses across the trial pillows compared with responses to subjects' 'own' pillow. Data were described in symptom categories 
per pillow, age and gender. Multivariate ANOVA models were used to test the significance of the effect of the block order of administration of trial pillows, age, gender and pillow type on waking symptom production (any, and weekly symptom duration scores). The likelihood of each symptom occurring on the trial pillows was considered in 2 ways, and reported as odds ratios (ORs, 95\% confidence intervals [CIs]). Firstly, each trial pillow was compared with subjects' 'own' pillow for any, versus no, waking symptoms, as well as symptom clusters (short-term versus longer-term waking symptoms). Secondly the association was considered between the trial pillows and any waking symptom production, arbitrarily using the polyester pillow as the default comparator.

\section{Results}

Subjects

One hundred six subjects commenced the study. Seven participants withdrew completely from the trial at various points throughout the subsequent 9 weeks: 3 due to production of cervicothoracic symptoms while trialing the feather pillow, and single participants due to emergency lumbar spine surgery following a fall, transfer from town for work purposes, a loss of interest in participating while trialing their usual pillow, and death of a spouse. There were also dropouts for each trial pillow. The sample demographics and the completions for each trial pillow week are outlined in Figure 1.

\section{Demographics}

There was congruence between gender and age distribution in the study sample, and the population characteristics of the rural town. ${ }^{16}$ The findings are therefore generalizable to the wider Australian population.

\section{Identifiable reason for waking symptoms}

The number of valid and excluded observations for analysis for each pillow accounted for any night of identifiable reasons (other than the pillow) for waking symptoms (see Figure 1).

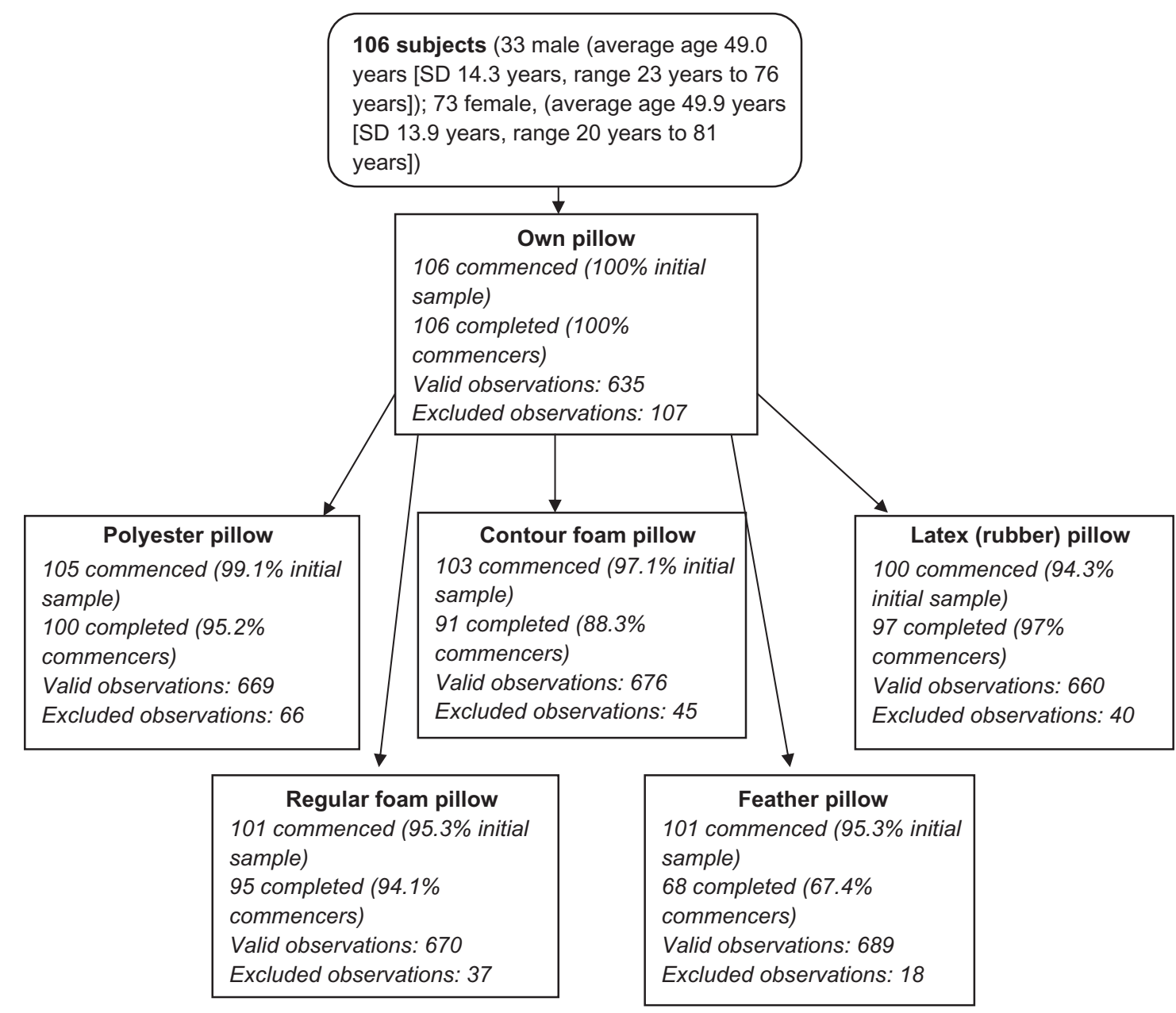

Figure I Sample demographics and completions, and valid and excluded observations for each pillow. 
These included the effects of alcohol, illness, wakeful spouse, children, pets, weather or external noises. There was no significant difference between pillows, gender or age groups regarding the excluded observations. The daily reports of known reasons for waking symptoms were greatest for subjects' 'own' pillow, followed by the feather pillow.

\section{Study completions}

All subjects completed the initial 'own pillow' trial week. However the number of subjects who completed each pillow trial varied, with the feather pillow having the lowest percentage of completers $(67.3 \%)$ and latex pillow having the highest percentage of completers $(97 \%)$ (see Figure 1).

\section{Block design effect}

There was no significant effect of the order of administration of the trial pillows on any symptoms, which suggests that subjects responded similarly to each trial pillow irrespective of the order in which they were tested.

\section{Baseline symptom reports}

When using their 'own' pillow, 33.9\% subjects reported any waking cervical stiffness, $19.6 \%$ reported any waking headache and $17.9 \%$ reported any waking scapular/arm pain (see Table 1).

\section{Waking cervical stiffness}

There was no significant effect of gender or age on weekly symptom duration scores for waking cervical stiffness (critical F values $_{\mathrm{df}=2} 0.97(P>0.05)$ and ${ }_{\mathrm{df}=1} 0.06(P>0.05)$ respectively). However there was a significant effect of pillow (critical F value $\mathrm{df5}_{5} 3.25(P<0.05)$ ) (Table 1). The largest weekly symptom duration score for waking stiffness occurred during the feather pillow trial, and significantly more subjects reported sustaining occasional half-day stiffness after sleeping on this pillow (considering symptom duration clusters). The likelihood of any reports of waking cervical stiffness occurring on subjects' 'own' pillow compared with the trial pillows, as well as symptom duration clusters of short-term versus longer-term stiffness, is reported in Table 2. These findings highlight the significant effect of the feather pillow on any occurrence of waking cervical stiffness, compared with subjects' 'own' pillow. It also indicates that once stiffness occurred, whatever subjects' 'own' pillow, the trial polyester, foam contour and feather pillows were significantly associated with longer symptom duration. When compared to the polyester pillow, no other trial pillow showed an elevated risk of waking cervical stiffness (see Table 2).

\section{Headache}

The percentage of subjects with valid observations who reported any waking headache on any pillow is reported

Table I Reports of waking cervical stiffness, headache and scapular pain, and trial pillow (using only valid data)

\begin{tabular}{|c|c|c|c|c|c|}
\hline Pillow & None & $\begin{array}{l}\text { Occasional } \\
\text { short term }\end{array}$ & $\begin{array}{l}\text { Regular short } \\
\text { term }\end{array}$ & $\begin{array}{l}\text { Occasional } \\
\text { long term }\end{array}$ & $\begin{array}{l}\text { Regular } \\
\text { long term }\end{array}$ \\
\hline \multicolumn{6}{|c|}{ Cervical stiffness } \\
\hline ‘Own’ pillow & $66.1 \%$ & $19.6 \%$ & $8.9 \%$ & $3.6 \%$ & $1.8 \%$ \\
\hline Polyester & $61.2 \%$ & $14.9 \%$ & $3.0 \%$ & $16.4 \%$ & $4.5 \%$ \\
\hline Foam regular & $61.5 \%$ & $17.9 \%$ & $6.4 \%$ & $6.4 \%$ & $7.7 \%$ \\
\hline Foam contour & $52.5 \%$ & $20.0 \%$ & $7.5 \%$ & $16.4 \%$ & $3.8 \%$ \\
\hline Feather & $49.2 \%$ & $7.7 \%$ & $4.6 \%$ & $33.9 \%$ & $4.6 \%$ \\
\hline Latex & $67.5 \%$ & $11.7 \%$ & $9.1 \%$ & $6.5 \%$ & $5.2 \%$ \\
\hline \multicolumn{6}{|l|}{ Headache } \\
\hline ‘Own’ pillow & $80.4 \%$ & $8.9 \%$ & $1.8 \%$ & $7.1 \%$ & $1.8 \%$ \\
\hline Polyester & $74.6 \%$ & $10.4 \%$ & $3.0 \%$ & $11.9 \%$ & $0 \%$ \\
\hline Foam regular & $73.4 \%$ & I I.4\% & $3.8 \%$ & I I.4\% & $0 \%$ \\
\hline Foam contour & $74.7 \%$ & $11.4 \%$ & $3.8 \%$ & $10.1 \%$ & $0 \%$ \\
\hline Feather & $63.3 \%$ & $18.3 \%$ & $0 \%$ & $16.7 \%$ & $1.7 \%$ \\
\hline Latex & $90.9 \%$ & $5.2 \%$ & $0 \%$ & $4.9 \%$ & $0 \%$ \\
\hline \multicolumn{6}{|c|}{ Scapular/arm pain } \\
\hline 'Own’ pillow & $82.1 \%$ & $10.7 \%$ & $1.8 \%$ & $3.6 \%$ & $1.8 \%$ \\
\hline Polyester & $76.1 \%$ & $10.5 \%$ & $0.0 \%$ & $8.9 \%$ & $4.5 \%$ \\
\hline Foam regular & $81.6 \%$ & $6.6 \%$ & $2.6 \%$ & $6.6 \%$ & $2.6 \%$ \\
\hline Foam contour & $77.2 \%$ & $10.1 \%$ & $1.3 \%$ & $10.1 \%$ & $1.3 \%$ \\
\hline Feather & $63.6 \%$ & $9.1 \%$ & $1.5 \%$ & $24.2 \%$ & $1.5 \%$ \\
\hline Latex & $88.3 \%$ & $3.9 \%$ & $1.3 \%$ & $6.5 \%$ & $0 \%$ \\
\hline
\end{tabular}


Table 2 Crude odds ratios $(95 \% \mathrm{Cl}$ ) of reporting waking cervical stiffness when comparing 'own' and each trial pillow, and when comparing the trial polyester pillow with the other trial pillows. Significant findings are in bold type

\begin{tabular}{|c|c|c|}
\hline & $\begin{array}{l}\text { No cervical stiffness } \\
\text { versus any cervical } \\
\text { stiffness }\end{array}$ & $\begin{array}{l}\text { Short term versus } \\
\text { longer term cervica } \\
\text { stiffness }\end{array}$ \\
\hline \multicolumn{3}{|c|}{ Compared with 'own' pillow } \\
\hline Polyester & $1.2(0.6-2.7)$ & $6.2(1.4-26.6)$ \\
\hline Foam regular & $1.2(0.6-2.5)$ & $2.7(0.6-12.4)$ \\
\hline Foam contour & $1.8(0.9-3.6)$ & $4.1(1.0-17.1)$ \\
\hline Feather & $2.0(1.0-4.2)$ & $16.3(3.7-27.9)$ \\
\hline Latex & $0.9(0.4-1.9)$ & $3.4(0.7-16.5)$ \\
\hline \multicolumn{3}{|c|}{ Compared with polyester pillow } \\
\hline Foam regular & $1.0(0.5-1.9)$ & $0.5(0.2-1.4)$ \\
\hline Foam contour & I.4 (0.7-2.7) & $0.6(0.2-1.7)$ \\
\hline Feather & $1.6(0.8-3.3)$ & $2.6(0.8-7.9)$ \\
\hline Latex & $0.8(0.4-1.5)$ & $0.5(0.2-1.6)$ \\
\hline
\end{tabular}

in Table 1. There were significant effects of gender, age and pillow on waking headache weekly duration scores (critical F values ${ }_{\mathrm{df}=2} 3.4,_{\mathrm{df}=1} 7.8$, and $\mathrm{df}=5_{5} 2.7$ respectively; $P<0.05$ in each instance). The significant differences occurred between the feather and latex pillows. These findings were congruent with those for stiffness, where the feather pillow was by far the most problematic. Fewer subjects reported being headache-free when trialing the feather pillow, and significantly more subjects reported being headache-free when trialing the latex pillow. The significant gender effect was explained by the finding that 2 women to every man reported a waking headache on any trial pillow. The age effect for waking headache was less clear, although for each experimental pillow, a higher frequency of middle-aged subjects (aged 40-59 years) consistently reported no waking headache, compared with the other age groups. Younger subjects consistently reported more waking headaches on their 'own' pillow and all trial pillows except latex, than the other age groups (see Figure 2).

The likelihood of any reports of headache occurring on subjects' 'own' pillow compared with the trial pillows is reported as crude and adjusted ORs and 95\% CI in Table 3. The crude findings were adjusted for the effects of age and gender, as both had significant univariate associations with frequency of occurrence. The feather pillow produced a significantly greater likelihood of any event of waking headache occurring compared with subjects' 'own' pillow. There were no other significant associations, although there was an emergent protective effect of latex pillows compared with 'own' pillow, highlighted by the Upper 95\% CI just spanning one (1.1). Once a headache occurred however, none of the pillows mitigated against headache duration (see Table 3).

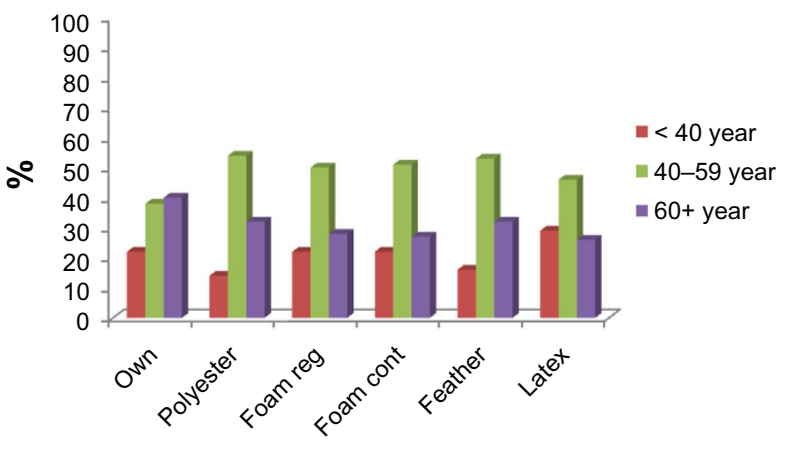

Figure 2 Age association with reports of no waking headache.

Only the latex pillow showed a significantly protective crude association for headache compared with the polyester trial pillow (see Table 3). This association was sustained after adjusting for gender and age. Once a headache occurred however, the type of trial pillow made no difference to headache duration.

\section{Scapular/arm pain}

The least number of subjects reported being free of scapular/ arm pain on waking on the feather pillow, whilst the greatest number reported being pain-free when waking on the latex pillow (see Table 1). Subjects' 'own' pillow and the regular foam pillow also produced low numbers of reports of waking scapular/arm pain. There were significant effects of gender and pillow on scapular/arm pain weekly duration scores (critical F value $\mathrm{df}=17.9$ and $3.4_{\mathrm{d}=5}$ respectively). The significant gender effect was produced by the male-female differences in weekly duration scores for scapular/arm pain for the foam regular, foam contour and feather pillows (see Figure 3). More women reported waking scapular/arm pain than men on these pillows, with the feather pillow producing the greatest gender effect.

The likelihood of any scapular/arm pain of any duration, occurring on subjects' 'own' pillow, compared with the trial pillows is reported as crude and adjusted ORs $(95 \%$ CI) in Table 4 . The crude association was adjusted for gender because of its significant univariate association with scapular/arm pain. The feather pillow was significantly more likely to be associated with any waking scapular/arm pain, compared with subjects' 'own' pillow. However no trial pillow was associated with symptom duration compared with 'own' pillow.

The latex trial pillow had a significantly protective crude association with scapular/arm pain compared with the polyester trial pillow. However the significant effect was lost when the association was adjusted for gender, and there was no 
Table 3 Crude and adjusted odds ratios $(95 \% \mathrm{Cl})$ of suffering headache when comparing 'own' and each trial pillow, and when comparing the trial polyester pillow with the other trial pillows.

\begin{tabular}{|c|c|c|c|}
\hline & & $\begin{array}{l}\text { No headache versus } \\
\text { any headache }\end{array}$ & $\begin{array}{l}\text { Short term versus } \\
\text { longer term headache }\end{array}$ \\
\hline \multicolumn{4}{|c|}{ Compared with 'own' pillow } \\
\hline \multirow[t]{2}{*}{ Polyester } & Crude & $1.4(0.6-3.3)$ & $0.9(0.2-3.1)$ \\
\hline & Adjusted & $1.4(0.5-3.2)$ & $0.8(0.2-3.1)$ \\
\hline \multirow[t]{2}{*}{ Foam regular } & Crude & I.5 (0.6-3.4) & $0.9(0.2-3.9)$ \\
\hline & Adjusted & $1.5(0.5-3.1)$ & $0.9(0.2-4.4)$ \\
\hline \multirow[t]{2}{*}{ Foam contour } & Crude & $1.4(0.6-3.2)$ & $0.8(0.2-3.5)$ \\
\hline & Adjusted & $1.4(0.6-3.1)$ & $0.6(0.1-3.4)$ \\
\hline \multirow[t]{2}{*}{ Feather } & Crude & $2.4(1.0-5.5)$ & $1.2(0.3-5.1)$ \\
\hline & Adjusted & $2.3(1.0-5.6)$ & $0.9(0.1-4.9)$ \\
\hline \multirow[t]{2}{*}{ Latex } & Crude & $0.4(0.2-1.1)$ & $0.9(0.1-6.1)$ \\
\hline & Adjusted & $0.4(0.2-1.1)$ & $0.8(0.1-10.2)$ \\
\hline \multicolumn{4}{|c|}{ Compared with polyester pillow } \\
\hline \multirow[t]{2}{*}{ Foam regular } & Crude & I.I $(0.5-2.2)$ & $0.8(0.2-2.8)$ \\
\hline & Adjusted & $1.1(0.5-2.3)$ & $0.8(0.2-3.1)$ \\
\hline \multirow[t]{2}{*}{ Foam contour } & Crude & $0.9(0.4-2.1)$ & I.3 (0.2-9.2) \\
\hline & Adjusted & I.I $(0.5-2.1)$ & I.I (0.2-8.2) \\
\hline \multirow[t]{2}{*}{ Feather } & Crude & $1.7(0.5-3.6)$ & $0.9(0.2-3.2)$ \\
\hline & Adjusted & $1.6(0.5-3.5)$ & $0.9(0.2-3.5)$ \\
\hline \multirow[t]{2}{*}{ Latex } & Crude & $0.3(0.1-0.8)$ & $0.9(0.2-3.2)$ \\
\hline & Adjusted & $0.3(0.1-0.8)$ & $0.8(0.2-3.2)$ \\
\hline
\end{tabular}

Note: Significant findings are in bold type.

differential effect of any trial pillow on scapular/arm pain duration (see Table 4).

\section{Discussion}

This paper provides the first known information about the association of different pillow shapes and fillers with waking symptoms of stiffness, headache and scapular/arm pain in side sleepers without cervicothoracic spine injury. Our findings suggest that a feather pillow should not be recommended if individuals seek a pillow better than their 'own' to reduce the frequency and duration of waking stiffness, headache and/or scapular/arm pain. Polyester and foam contour pillows should not be recommended to subjects who suffer from waking cervical stiffness. However, latex pillows can be recommended when subjects seek to decrease waking headache or scapular/arm pain. Foam pillows (contour and regular shaped) were similarly associated with waking headache and scapular/arm pain. Hence, recommendation of a foam contour pillow over a foam regular pillow for side sleepers with these symptoms is inappropriate. The benefits of a latex pillow for minimizing waking headache and scapular/arm pain, and heightened symptom occurrence with feather pillows, concurs with our previous findings for waking cervical pain. ${ }^{14}$

These findings are congruent with recent research into the effect of pillows on symptomatic cervical spines, as a pillow moulded to, or specifically supportive of, the neck, was found to be protective of waking pain..$^{9,10}$

\section{Invalid findings}

Reasons for waking symptoms (other than the pillow) were consistently reported over the study period. The highest number of invalid findings was reported on subjects' 'own' pillow during the first week of the study. Whilst this highlights that sleep is regularly disturbed for a high percentage of uninjured people, it also raises concerns that subjects were perhaps most aware of classifying reasons for waking symptoms on their 'own' pillow at study commencement, rather than later in the study period, when they may have been more focused on trial pillow performance.

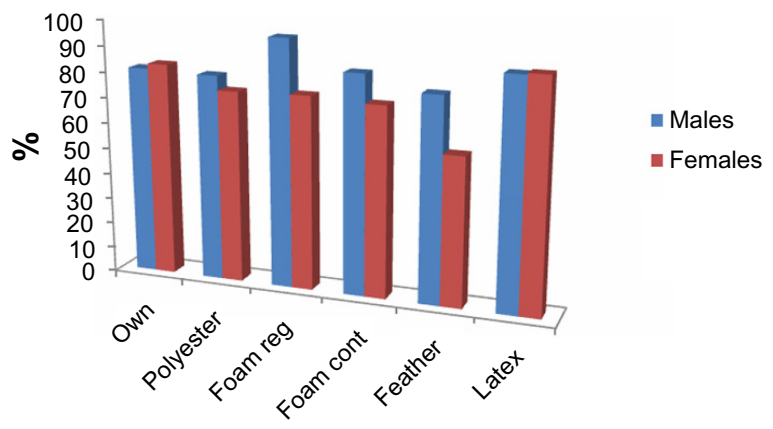

Figure 3 Gender differences in reports of no waking scapular/arm pain on each trial pillow. 
Table 4 Crude and adjusted odds ratios $(95 \% \mathrm{Cl})$ of suffering scapular/arm pain when comparing own and each trial pillow, and when comparing the trial polyester pillow with the other trial pillows

\begin{tabular}{llll}
\hline & & No scapular/arm pain & $\begin{array}{l}\text { Short term versus } \\
\text { longer term } \\
\text { scapular/arm } \\
\text { pain }\end{array}$ \\
pain
\end{tabular}

Notes: Significant findings are in bold type.

\section{Drop outs}

All study dropouts occurred before the fifth trial day, and hence 7 days appears to be a suitable period for an experimental pillow study. The 'washout period' of 'own' pillow use for 7 days between experimental pillows also appeared to be appropriate to reduce trial pillow symptoms and participant fatigue. Despite the high number of drop-outs on the feather pillow, the total number of valid observations on this pillow collated over the trial week exceeded the estimated sample size for robust observations on any one pillow (500), thus alleviating concerns about appropriate power to detect differences between pillows.

\section{Symptom reports}

Other than our previous work, little has been reported on the prevalence of waking stiffness and scapular/arm pain. However, Jull et a ${ }^{18}$ reported that $58 \%$ of cervicogenic headache sufferers reported their headache on waking. Our study could not determine the anatomical mechanisms underlying waking headache, stiffness or scapular/arm symptoms. Waking symptom causality is likely to be complex and involve increased biomechanical load on more than one anatomical structure. ${ }^{2,718}$ Our findings provide support for the need for targeted laboratory research to establish the anatomical structures and biomechanical mechanisms underlying waking symptoms, and how pillow type contributes to this. Moreover, as latex pillows appear to be consistently effective in reducing the frequency of any waking symptom in a noninjured population, trials of this pillow for symptomatic subjects is now indicated.

\section{Study biases}

Despite using a rigorous research design to reduce bias from measurement or allocation to pillows, limitations of this study included an inability to completely blind subjects to pillow type, reliance on daily self-report measures of symptom occurrence and duration, and limited information about subjects' 'own' pillows. A high number of waking symptom reports on subjects' 'own' pillows may have been related to increased vigilance in responses during the first week of the trial, or may simply validate the previously reported, high percentage of noninjured healthy people who experience regular waking symptoms. ${ }^{11}$ If increased vigilance were the reason for high frequency reports of waking symptoms on 'own' pillow, then reports of waking symptoms on the subsequent trial pillows may have been related to reasons other than the pillow, but were ascribed to the pillow as a result of expectation or anticipation bias. ${ }^{19}$ The potential for 
over- and under-reporting of symptoms during the trial pillow weeks should also be considered. Thus further pillow field trials should be undertaken with randomly selected subjects, whose 'own' pillows are well described, with predetermined sensitivities to different trial pillows because of their choice of 'own' pillow, and who provide greater detail on their usual sleep behaviors and waking symptoms.

\section{Conclusion}

This study highlights the common nature of sleep disturbance in the never-injured population, and the variability of waking symptoms related to different pillow types. The study findings indicate the consistently good performance of latex pillows in reducing the frequency of waking headache and scapular/ arm pain, and thus these pillows should be recommended to reduce waking symptoms. Feather pillows should not be recommended as they are associated with greater likelihood of waking symptoms.

\section{Disclosure}

The authors report no conflicts of interest in this work.

\section{References}

1. McDonnell J. Sleep posture: its implications. Br J Phys Med. 1946;9:46-52.

2. Jackson R. The Cervical Spine. 3rd ed. Springfield, Il Charles C. Thomas; 1976.

3. Bland J. Disorders of the Cervical Spine. Philadelphia, PA Saunders; 1987.

4. Grieve GP. Common Vertebral Joint Problems. 2nd Edition. Edinburgh, UK: Churchill Livingston; 1988.
5. Kramer J. Intervertebral Disk Diseases: causes, diagnosis, treatment and phophylaxis. New York, NY: Thieme Medical Publishers Inc; 1990.

6. Helewa A, Goldsmith C, Smythe H, Lee P, Obright K, Stitt L. Effect of therapeutic exercise and sleeping neck support on patients with chronic neck pain: A randomized control trial. J Rheumatol. 2007;34(1):151-158.

7. Bogduk N. Neck pain: assessment and management in general practice. Modern Medicine in Australia. 1995;32:102-108

8. Shields N, Capper J, Polak T, Taylor N. Are cervical pillows effective in reducing neck pain? NZ J Physio. 2006:34(1):3-9.

9. Persson L. Neck pain and pillows - A blinded study of the effect of pillows on non-specific neck pain, headache and sleep. Adv Physiother. 2006;8(3):122-127.

10. Bernateck M, Karst M, Merkesdal S, Fischer MJ, Gutenbrunner C. Sustained effects of comprehensive inpatient rehabilitative treatment and sleeping neck support in patients with chronic cervicobrachialgia: A prospective and randomized clinical trial. Int $J$ Rehab Res. 2008;31(4):342-346.

11. Gordon SJ, Trott P, Grimmer KA. Waking cervical pain and stiffness, headache, scapular or arm pain: Gender and age effects. Aust $J$ Physiother. 2002;48:9-15.

12. De Koninck J, Lorrain D, Gagnon P. Sleep positions and position shifts in five age groups: an ontogenetic picture. Sleep. 1992;15:143-149.

13. Gordon S, Grimmer-Somers K, Trott P. Sleep position, age, gender, sleep quality and waking cervico-thoracic symptoms. Internet J Allied Health Sci Pract. 2007;5:1.

14. Gordon S, Grimmer-Somers K, Trott P. Pillow use: The behaviour of cervical pain, sleep quality and pillow comfort in side sleepers. Man Ther. 2009;14(6):671-678.

15. Anthony D. Understanding Advanced Statistics. New York, NY: Churchill Livingstone; 1999.

16. Australian Bureau of Statistics. Census 2001, Canberra. Available from http://www.abs.gov.au. Accessed on Mar 10, 2010.

17. Yin RK. Case Study Research: Design and Methods (Applied Social Research Methods Series). 3rd ed. New York, NY: Sage Press; 2003.

18. Jull G, Bogduk N, Marsland A. The accuracy of manual diagnosis for cervical zygapophysial joint pain syndromes. Med J Aust. 1988;148:233-236.

19. Sackett DL. Bias in analytic research. J Chron Dis. 1979;32:51-63.
Journal of Pain Research

\section{Publish your work in this journal}

The Journal of Pain Research is an international, peer-reviewed, open access, online journal that welcomes laboratory and clinical findings in the fields of pain research and the prevention and management of pain. Original research, reviews, symposium reports, hypothesis formation and commentaries are all considered for publication.

\section{Dovepress}

The manuscript management system is completely online and includes a very quick and fair peer-review system, which is all easy to use. Visit http://www.dovepress.com/testimonials.php to read real quotes from published authors. 